the subcontrary sections are also circles.* On pages 40 and 41 occurs a passage where the revision was not edited so carefully as usual: Kepler is still, as in the first edition, credited with the cubature of the torus, whereas in the preceding paragraph (an addition in the new edition) this result is described as found in Heron of Alexandria. In this connection "the so-called theorem of Guldin" is mentioned. (See also p. 8.) Is it not time that Guldin's name was entirely dropped, and the theorem referred to exclusively as "the theorem of Pappus"? The reasons for doing this are clearly stated by Tropfke himself in the passage in question.

The index has evidently been very carefully compiled, which is of course an absolute necessity where the number of references is so great. The reviewer has checked a large number of these, and has noted the following corrections: p. 77, Kahun, I 134 should read, II 134; p. 101, Addition, II 65 should be I 65 . Two other misprints should be mentioned: p. 51, 1. 4, "Oktaeders" should read "Dodekaeders;" and in vol. IV, p. 139, 1. 17, "4000 v. Chr." should read "2000 v. Chr."

Two topics that the reviewer believes should have been included have been entirely omitted: the regula falsi, and the "Russian peasant method of multiplication". Each is of historical interest and not without significance as furnishing supplementary material for class-room work or for outside reference, as in mathematics club programs.

We must end as we began, that this work is unique and of the highest excellence in its field, and a monument to the skill and industry of its author.

R. B. McClenon

Binomial Factorizations, Giving Extensive Congruence Tables and Factorization Tables. Vols. II, III, and VI. By Lt. Col. Allan Cunningham. London, Francis Hodgson.

Of the seven volumes of this work the reviewer has in hand Volumes I, II, III, IV and VI. The content and general make-up of these tables has been considered in a previous review in the BuLletis (vol. 31, pp. 180-181). By means of certain congruence-tables, giving the smallest roots, $y$, of the congruence

$$
\frac{y^{n \pm 1}}{y \pm 1} \equiv 0
$$

the author has built up factorization tables for numbers of certain special forms.

The value of such tables depends entirely upon their accuracy. An examination of certain of the tables, selected at random, leaves one in a state of doubt as to the value of the whole. 'Thus on page 193

\footnotetext{
* T. L. Heath, Apollonius of Perga, Cambridge, 1896, pp. 2, 3.
} 
of Volume II are two little tables purporting to give the factors of what he calls "Trin-Aurifeuillian Quindecimans" and "Quint-Aurifeuillian Quindecimans", which, in plain English are factorizations of numbers of the forms $x^{15} \pm y^{15}$ after the algebraic divisors have been removed. Certain of the entries are left undecomposed, but at the head of the tables we are informed "All divisors less than 1,000 cast out". Nevertheless the following numbers on this page are left with a question mark:

$$
\begin{aligned}
& 17,780,401=151 \times 117,751 \\
& 17,354,461=181 \times 95,881 \\
& 15,679,621=211 \times 74,311 .
\end{aligned}
$$

The last number in the first table is $10,545,971$ which is an error for $10,545,991=151 \times 211 \times 331$. Also the number $25,437,261$ should be $125,437,261$. Moreover the complete examination of all the numbers left doubtful on this page ought not to occupy a skilful computer many hours. One questions the usefulness or importance of publishing a table of factors of "Trinomial Dimorph Sextans", of eight entries, containing only five complete factorizations, and leaving five factors undecomposed two of which, $12,419,509=2029 \times 6121$, and $13,401,901=1297 \times 10,333$, would have yielded without much effort.

In spite of the fact that the author had access (p. 171, vol. I.) to the recently published factor-tables he leaves doubtful, in Volume I such numbers as

$$
\begin{aligned}
& 9,705,193, \text { p. } 171 \text {, vol. I, } \\
& 9,670,849, \text { p. } 211 \text {, vol. I, } \\
& 9,843,601 \text {, p. } 217 \text {, vol. I, }
\end{aligned}
$$

and in Volume II we are given (p. 189) a question mark after 4, 144, 741.

These inaccuracies are, of course, not important in themselves, but show pretty clearly that these tables cannot be used in important work without careful checking.

\section{N. LeHMER}

Einführung in die Projective Geometrie Mehrdimensionaler Räume. By E. Bertini. Translated from the second Italian edition by A. Duschek. Wien, Seidel \& Sohn, 1924. 480 pp.

In 1860 Cremona, then thirty years of age, became Professor of Higher Geometry at the ancient University of Bologna. About thirty years later Italy led the world in research in geometry. Due chiefly to Cremona's influence, the field of projective geometry in hyperspace was developed with great vigor. Today this subject can be said to be almost wholly Italian. Much good work on the subject has been done outside of Italy but nowhere else has there been such an army of the ablest mathematicians working at it. Professor Bertini of the University of Pisa has contributed his share in this work and it is, 